\title{
Analysis of Emotional Intelligence Level of Class IX Students of SMP Negeri 1 Dukuhseti, Pati Regency
}

\author{
Kholishotin Mu'arofah ${ }^{1}$, M.Th. S. R. Retnaningdyastuti ${ }^{2}$, Padmi Dyah Yulianti ${ }^{3}$ \\ Universitas PGRI Semarang, Indonesia \\ Email:otinwae93@gmail.com
}

\begin{abstract}
Emotional intelligence is the ability of a person to know himself better and to know others so that he is able to establish harmonious relationships with others. Students who have high emotionality will be able to overcome the various problems they face and achieve success. This research uses quantitative research and is analyzed using descriptive research method with sample t-test technique tryout used. One variable in this research is emotional intelligence. The population in this study is 68 students. The sample of this research uses a random sampling method). with a specific purpose. The sample is taken as many as 68 students. The data collection uses a Likert scale. The data analysis method is assisted by using the SPSS (Statistical Product and Service Solution) program. A total of 12 students or $17.65 \%$, have a low level of emotional intelligence, as many as 30 students or $44.12 \%$ have a moderate level of emotional intelligence, as many as 24 students or $35.29 \%$ have a high level of emotional intelligence and as many as 2 students or $2.94 \%$ have a very high level of emotional intelligence. At the moderate level is $\mathrm{k}$ the fact that knowledge of emotional intelligence is still rarely provided by formal education in improving students' emotional intelligence abilities.
\end{abstract}

Keywords: Analysis of Emotional Intelligence Ability Level, Junior High School, Class IX

\section{Analisis Tingkat Kemampuan Kecerdasan Emosional Siswa Kelas IX SMP Negeri 1 Dukuhseti Kabupaten Pati}

\begin{abstract}
Abstrak
Kecerdasan emosional merupakan kemampuan seseorang mengenal dirinya sendiri dengan lebih baik dan mengenal orang lain sehingga mampu menjalin hubungan yang harmonis dengan orang lain. Siswa yang mempunyai emosional yang tinggi akan mampu mengatasi berbagai masalahyang dihadapinya dan mencapai kesuksesan. Penelitihan ini menggunakan jenis penelitihan kuantitatif dan dianalisis dengan menggunakan metode penelitihan deskriptif teknik sample t-test triout terpakai. Satu variabel dalam penelitihan ini adalah kecerdasan emosi Populasi dalam penelitihan ini adalah siswa yang berjumlah 68 siswa. Sample penelitihan ini menggunakan metode sampling sample random sampling dengan tujuan tertentu. Sampel yang di ambil sebanyak 68 siswa. Penggumpulan datanya menggunakan skala Likert, metode analisis data dibantu dengan menggunakan program SPSS (Statistical Product and Service Solution). Sebanyak 12 siswa atau 17,65\% memiliki tingkat kecerdaan emosional rendah, sebanyak 30 siswa atau 44,12\% memiliki tingkat kecerdasan emosional sedang, sebanyak 24 siswa atau 35,29\% memiliki tignkat kecerdasan emosional tinggi dan sebanyak 2 siswa atau 2,94\% memiliki tingkat kecerdasan emosional sangat tinggi. Banyaknya siswa yang memiliki tingkat kecerdasan emosional yang masih berada pada tingkat sedang adalah kenyataan bahwa pengetahuan kecerdasan emosional masih jarang diberikan oleh pendidikan formal dalam meningkatkan kemampuan kecerdasan emosional siswa.
\end{abstract}

Kata Kunci: Analisis Tingkat Kemampuan Kecerdasan Emosional, SMPN, Kelas IX 


\section{PENDAHULUAN}

Tujuan pendidikan nasional sebagaimana disebutkan dalam undang-undang RI No.20 tahun 2003 bab II pasal 3 adalah untuk mewujudkan suasana dan proses pembelajaran agar peserta didik secara aktif mengembangkan potensi dirinya untuk memiliki kekuatan spiritual keagamaan, pengendalian diri, kepribadian, kecerdasan, akhal mulia serta ketrampilan yang diperlukan dirinya, masyarakat, bangsa, dan negara. Pendidikan nasional berfungsi mengembangkan kemampuan dan membentuk watak serta beradaban bangsa yang bermartabat dalam rangka mencerdaskan kehidupan bangsa, bertujuan untuk berkembangnya potensi peserta didik agar menjadi manusia yang beriman dan bertakwa kepada Tuhan Yang Maha Esa, berakhlak mulia, sehat, berilmu, cakap, kreatif, mandiri, dan menjadi warga negara yang demokratis serta tanggung jawab (dalam http://simkeu.kemdikbud.go.id/index.php/peraturan1)

Menurut Howard Gardner dalam Indah Mayang (2016: 236) Kecerdasan emosi terdiri atas banyaknya kecakapan, di antaranya intrapersonal intellegence dan interpersonal intellegence. Intrapersonal intellegence merupakan kecakapan mengenali perasaan diri sendiri atas: 1) Kecerdasan diri meliputi kecerdasan emosi, penelitihan pribadi, dan percaya diri. 2) Pengaturan diri, meliputi pengendalian diri, dapat dipercaya, waspada, adptif dan inovatof. 3) Motivasi, meliputi dorongan berprestasi, komitmen, inisiatif, dan optimis. Adapun interpersonal intellegence merupakan kecakapan yang berhubungan dengan orang lain yang terdiri atas. 1) Empati, meliputi memahami orang lain, pelayanan mengembangkan orang lain, mengatasi ketergantungan, dan kesadaran politis. 2) Ketrampilan sosial, meliputi pengaruh, komunikasi, kepemimpinan katalisator perubahan, manajemen konflik, pengikat jaringan, kolaborasi, dan koperasi serta kerja tim.

Menurut Future of Jobs Report dari World Economic Forum, kecerdasan emosional akan menjadi salah satu dari 10 keterampilan ketenagakerjaan teratas pada tahun 2020 dan setelahnya Beckford (2018). Sebelumnya pada tahun 1995 Daniel Goleman pertama kali meningkatkan kesadaran akan EQ, dalam bukunya Emotional Intelligence. Sejak dirilis pada 1995, penelitian telah membuktikan bahwa kecerdasan emosi memprediksi keberhasilan di masa depan dalam hubungan, kesehatan, dan kualitas hidup. Penelitian sebelumnya menyatakan bahwa untuk menjadi sukses, kecerdasan emosional memiliki peran penting yang sama sebagaimana kecerdasan dalam matematika. Karena itu, pemberi kerja semakin mencari lebih banyak orang dengan kecerdasan emosional. Para peneliti telah menunjukkan keberhasilan di tempat kerja atau dalam kehidupan tergantung pada Kecerdasan Emosional 80\% dan hanya 20\% dari kecerdasan intelektual Cotrus, $\operatorname{dkk}(2013: 211)$

Kecerdasan emosional yaitu kemampuan seseorang dalam menerima, menilai, mengelola, serta mengontrol emosinya secara cerdas berdasarkan indikator-indikator kecerdasan emosional seperti : mengendalikan emosi orang lain (empati), kemampuan untuk membina hubungan (kerjasama) dengan orang lain, serta memahami dan mengontrol emosi diri sendiri dan orang lain secara akurat, sehingga dapat menggunakan emosi dengan baik dan mengelolahnya menjadi sebuah kecerdasan yang berguna untuk hal-hal yang positif. Indikator kecerdasan emosional terdapat 5 bagian,yaitu: 1) Kesandaran diri 2) Pengaturan diri 3) Motivasi diri sendiri 4) Mengelolah emosi orang (empati) 5) Membina hubungan.

Berdasarkan penelitian yang di lakukan oleh Herlinda, dkk (2018) dari hasil Daftar Cek Masalah (DCM) yang di lakukan di SMP N 03 Mukomuko. Dilakukan hasil observasi dan wawancara dengan guru di SMP N 03 Mukomuko, di peroleh hasil bahwa permasalahan sosial yang sebagian di alami siswa tersebut di sebabkan kerena ketidak mampuan siswa dalam berinteraksi dan kurang mampunya mengembangkan kecerdasan emosi siswa. Ini terlihat ketika siswa asik 
ngobrol dengan temannya diluar kelas pada saat istirahat, siswa tersebut memilih menyendiri di dalam kelas. Ada siswa yang suka marah jika di tegur. Apabila siswa tidak bisa mengendalikan emosinya, makasiswa tidak mampu beempati terhadap orang lain. Ada yang menyendiri karena memiliki kecerdasan di bawahrata-rata teman lainnya.

Berdasarkan penelitihan yang di lakukan Indah Mayang (2016) menjelaskan bahwa hasil penyebaran angket identifikasi kecerdasan emosional siswa yang dilakukan terhadap 98 siswa di SMAN di Madya Jakarta Selatan Skor kecerdasan emosional siswa yang di peroleh dari para responden mempunyai rata-rata 130,48 dengan simpangan baku 11,881, median 130,00,skor minimum 104 dan skor maksimum 170.banyaknya butir pertanyaan dalam intrumen kecerdasan emosional adalah 34 butir dengan skor maksimum tiap butir pertanyaan adalah 5,maka skor ratarata tiap pertanyaan adalah 3,8376 atau $76,75 \%$ dari rata-rata hal ini menunjukan bahwa rata-rata skor kecerdasan emosional siswa termasuk sedang. Skor simpangan baku 11,88 atau sama dengan $9,1 \%$ dari rata-rata,menunjukkan perbedaan jawaban atas responden termasuk rendah. Hal ini menunjukkan bahwa tingkat kecerdasan emosional responden tidak banyak beragam.

Bagaimanapun, sekolah merupakan tempat yang cukup menantang bagi siswa pada berbagai tingkatan. Beberapa siswa mungkin juga menghadapi kekerasan di lingkungan sekolah siswa. Masalah-masalah ini tidak diragukan lagi mempengaruhi kinerja akademik, perilaku, dan kesehatan emosionalnya. Memberikan dukungan kepda para siswa mengenai masalah kecerdasan emosi, menyebabkan siswa mendpatkan hasil positif dalam kecerdasan emosi, hal ini mendorong keberhasilan sekolah, dan mempromosikan budaya sekolah yang konstruktif.Karena itu, sekolah sangat penting dalam mendukung siswa dalam keberhasilan akademik dan emosional.

Sekolah memainkan peran besar dalam kesehatan emosional anak-anak Ross \& Powell (2002: 43-52). Ross melakukan penelitian tentang pentingnya kecerdasan emosional dan peran yang dimainkan psikolog bagi kesehatan anak sekolah. Siswa paling banyak menemukan masalah sosial yang dihadapi dimulai pada usia yang sangat muda namun hal tersebut dapat dicegah.Beberapa masalah-masalah yang dalami siswa diantaranya adalah penyalahgunaan zat adiktif, kinerja sekolah negatif, dan tingkah laku seksual. Ross menjelaskan bahwa secara psikologis anak muda yang kompeten lebih cenderung menghindari kegiatan berisiko tinggi yang dapat terjadi konsekuensi berbahaya bagi kesehatan dan kesejahteraan mereka. Namun demikian sekolah memiliki kemampuan untuk mengajar kompetensi emosional dan sosial siswa. Pendidikan kecerdasan emosional dapat dilakukan dengan mengajarkan siswa mengenai bagaimana mengidentifikasi emosi siswa sendiri dan menafsirkan pengalaman mereka secara logis. Keterampilan dipelajari melalui pendidikan kecerdasan emosional adalah keterampilan hidup dan mereka sama saja penting sebagai prestasi akademik bagi siswa SLTP yang masih berada pada masa remaja awal.

\section{METODE}

Pendekatan dalam penelitian ini menggunakan metode kuantitatif dengan teknik deskriptif. Penelitian deskriptif adalah penelitihan yang dimaksudkan untuk menyelidiki keadaan, kondisi, atau hal lain yang sudah disebutkan, yang hasilnya dipaparkan dalam bentuk laporan penelitihan. Dalam penelitian ini peneliti tidak melakukan apa-apa terhadap objek atau wilayah penelitan. Peneliti hanya memotret apa yang terjadi pada diri objek atau wilayah yang diteliti, kemudian memaparkan apa yang terjadi dalam bentuk laporan penelitihan secara lugas seperti apa adanya. Populasi dalam penelitian ini adalah siswa kelas IX SMPN 1 Dukuhseti Pati sebanyak 68 siswa.Sampel yang di ambil merupakan siswa kelas IX SMPN Dukuhseti sebanyak 68 siswa.Pengumpulan data Dalam penelitian ini menggunakan skala likert untuk mnegumpulkan data. Skala likert digunakan untuk 
mengukur sikap, pendapat, dan persepsi seseorang atau sekelompok orang tentang fenomena sosial. Sedangkan skala yang diberikan berupa pernyataan-pernyataan yang disertai alternatif jawaban yang sesuai dengan keinginan. Pernyataan-pernyataan yang akan diberikan adalah sesuai dengan kebutuhan yaitu tentang kecerdasan emosi siswa SMPN 1 Duhuhseti.Skala likert terdiri dari lima alternatif pilihan, namun diubah menjadi 4 pilihan dengan alasan pilihan jawaban yang barupa "ragu-ragu" dianggap tidak efektif dalam menggali keterangan siswa. Kebanyakan siswa akan memilih alternatif jawaban "ragu-ragu" di mana akan menyulitkan peneliti dalam mengolah data penelitian. Empat pilihan tersebut antara lain, untuk item fafourable yaitu Sangat Sesuai (SS) = skor 4, Sesuai $(\mathrm{S})=$ skor 3 . Tidak Sesuai $(\mathrm{TS})=$ skor 2 , Sangat Tidak Sesuai $(\mathrm{STS})=$ skor 1 . Sedangkan untuk item Unfafourable Sangat Setuju (SS) = skor 1, Sesuai $(\mathrm{S})=$ skor 2, Tidak Sesuai $(T S)=$ skor 3, Sangat Tidak Sesuai (STS) = skor 4.Sebelum dilakukan uji hipotesis maka di cari terlebih dahulu seberapa besar tingkat kemampuan kecerdasan emosional. Metode analisis data yang digunakan oleh penulis dalam penelitian ini adalah menggunakan teknik analisis deskriptif. Statistik deskriptif adalah statistik yang digunakan untuk menganalisis data dengan cara mendeskripsikan atau menggambarkan data yang telah terkumpul sebagaimana adanya tanpa bermaksud membuat kesimpulan yang berlaku untuk umum atau generalisasi Sugiyono (2017, hal. 207). Pada penelitian ini penyajian data menggunakan tabel dan analisis datanya menggunakan mean.Utuk mempermudah perhitungan dalam penelitian ini, analisis data yang dilakukan menggunakan bantuan komputer program SPSS (Stractial Product for Survece Solution)

\section{HASIL DAN PEMBAHASAN}

Pengujian hipotesis dalam penelitian ini menggunakan alat bantu program SPSS Statistics. Program ini merupakan program komputer yang dipakai untuk analisis statistik. Pada penelitian ini pengujian hipotesis dilakukan dengan teknik teknik analisis deskriptif.Penyusunan skala atau alat ukur adalah komponen yang vital dalam penelitian ini. Persiapan berupa penyusunan alat ukur yang dilakukan oleh peneliti diawali dengan menentukan skala yang akan digunakan dalam penelitian. Skala dalam penelitian ini disusun dengan mendasarkan pada aspek-aspek yang akan digunakan dan selanjutnya disusun menjadi beberapa item pernyataan. Sementara skala yang digunakan dalam penelitian ini adalah skala kecerdasan emosional. Masing-masing skala dalam penelitian ini disajikan dalam dua jenis pernyataan, yaitu pernyataan yang mendukung (faforable) dan pernyataan yang tidak mendukung (unfaforable) dan memiliki lima alternatif jawaban.

Skala kecerdasan emosioanl dengan mengembangkan lima aspek yaitu :Mengenali Emosi, Mengelola Emosi, Memotivasi Diri Sendiri, Mengenali Emosi Orang Lain, dan Membina Hubungan. Skala kecerdasaan emosional yang terbentuk terdiri dari 40 item dan terlebih dahulu diujicobakan yang terdiri dari 20 item favorable dan 20 item unfaforableGuna menjaga kehandalan alat ukur atau skala, uji vaiditas dan reliabilitas dilakukan setelah alat ukur diberikan pada subjek penelitian. Uji validitas item diukur dengan menggunakan rumus korelasi Product Moment dari Pearson. Reliabilitas dalam enelitian ini diuji menggunakan rumus Cronbach Alpha. Perhitungan dilakukan dengan dengan bantuan software SPSS (Statistical Product and Service Solution) versi 22.0 for Windows.

Uji coba item dilaksanakan pada akhir bulan Nopember 2020 dengan jumlah subjek sebanyak 68 siswa. Berdasarkan hasil uji validitas yaitu sebanyak 40 item, diperoleh sebanyak 34 item memiliki validitas yang baik. Hal ini ditunjukkan dengan nilai korelasi item-total yang lebih besar dari 0,316. Dengan demikian hasil pengujian menunjukkan bahwa sebanyak 6 item dinyatakan gugur karena memiliki nilai korelasi di bawah angka 0,316 . Hasil pengujian atau estimasi reliabilitas 
skala Kecerdasan Emosional setelah mengeluarkan item 4,6,19,23,31 dan 38 dengan menggunakan koefisien reliabilitas alfa atau cronbach's alpha. Hasil pengujian cronbach's alpha diperoleh sebesar 0,945 yang lebih dari 0,70. Menurut Hair, Black, Anderson, \& Tatham (2011) nilai cronbach's alpha di atas 0,60 merupakan instrumen yang reliabel.

Untuk mempersentasikan tingkat kecerdasan emosi yang dimiliki siswa pada subjek penelitian, peneliti menggunakan skala kecerdasan emosi blue print baru yang terdiri dari 34 item yang selanjutnya digunakan untuk analisis dengan menggunakan sampel sebanyak 68 siswa.

Tabel 1. Distribusi Kelas Interval Nilai Kecerdasan Emosional

\begin{tabular}{cc}
\hline Nilai Interval & Keterangan \\
\hline $36,00-57,60$ & Sangat rendah \\
$57,61-79,20$ & Rendah \\
$79,21-100,80$ & Sedang \\
$100,81-122,40$ & Tinggi \\
$122,41-144,00$ & Sangat Tinggi \\
\hline
\end{tabular}

Hasil penelitian tentang tingkat kecerdasan emosional yang dimiliki oleh siswa kelas IX SMPN Dukuhseti Pati disajikan dalam analisis deskriptif.Analisis deskriptif data merupakan gambaran secara umum yang menyajikan penyebaran data hasil penelitian yang diperoleh agar lebih mudah dipahami. Dalam pelaksanaan penelitian masing-masing siswa yang menajdi sampel mendapatkan 1 bendel instrumen kuesioner yang dikirimkan ke masing-masing. Peneliti bertindak sebagai observer atau pengamat serta pengambilan dokumentasi. Penelitian ini menggunakan konsep try out terpakai, dimana data penelitian yang digunakan adalah data tryout setelah mengeluarkan datadata yang tidak valid (gugur). Hasil analisis deskriptif dapat dilihat dari tabel 2 berikut:

Tabel 2. Statsitik Nilai Kecerdasaan Emsional

\begin{tabular}{lc}
\hline Keterangan & Nilai \\
\hline Rata-rata (Mean) & 94,96 \\
Nilai tengah (Median) & 96,50 \\
Nilai yang paling sering muncul (Modus) & 106,00 \\
Ragam (Variansi) & 177,86 \\
Simpangan Baku (Standard Deviasi) & 13,34 \\
Nilai terendah (Minimum) & 73,00 \\
Nilai Tertinggi (Maximum) & 127,00 \\
Jangkauan (Range) & 54,00 \\
\hline
\end{tabular}

Sumber: Data Primer diolah, 2020

Berdasarkan tabel 2 pada data Kecerdasan Emsional diperoleh dengan skor rata-rata sebesar 94,96; median sebesar 96,50; modus sebesar 106,00; varian data sebesar 177,86; simpangan baku/standar deviasi data sebesar 13,34; skor minimum sebesar 73,00 skor maksimum sebesar 127,00; dan rentang data sebesar 54,00. 
Tabel 3. Distribusi Frekuensi Nilai Kecerdasan Emosional

\begin{tabular}{cccc}
\hline Nilai Interval & Keterangan & $\mathbf{f ~ ( f r e k u e n s i ) ~}$ & $\mathbf{\%}$ \\
\hline $36,00-57,60$ & Sangat rendah & 0 & 0.00 \\
$57,61-79,20$ & Rendah & 12 & 17.65 \\
$79,21-100,80$ & Sedang & 30 & 44.12 \\
$100,81-122,40$ & Tinggi & 24 & 35.29 \\
$122,41-144,00$ & Sangat Tinggi & 2 & 2.94 \\
\hline Jumlah & & 68 & 100.00 \\
\hline
\end{tabular}

Sumber: Data Primer diolah, 2020

Penyajian data distribusi frekuensi kategori tingkat kcerdasan emosional nilai dapat dilihat pada Gambar 1 berikut ini.

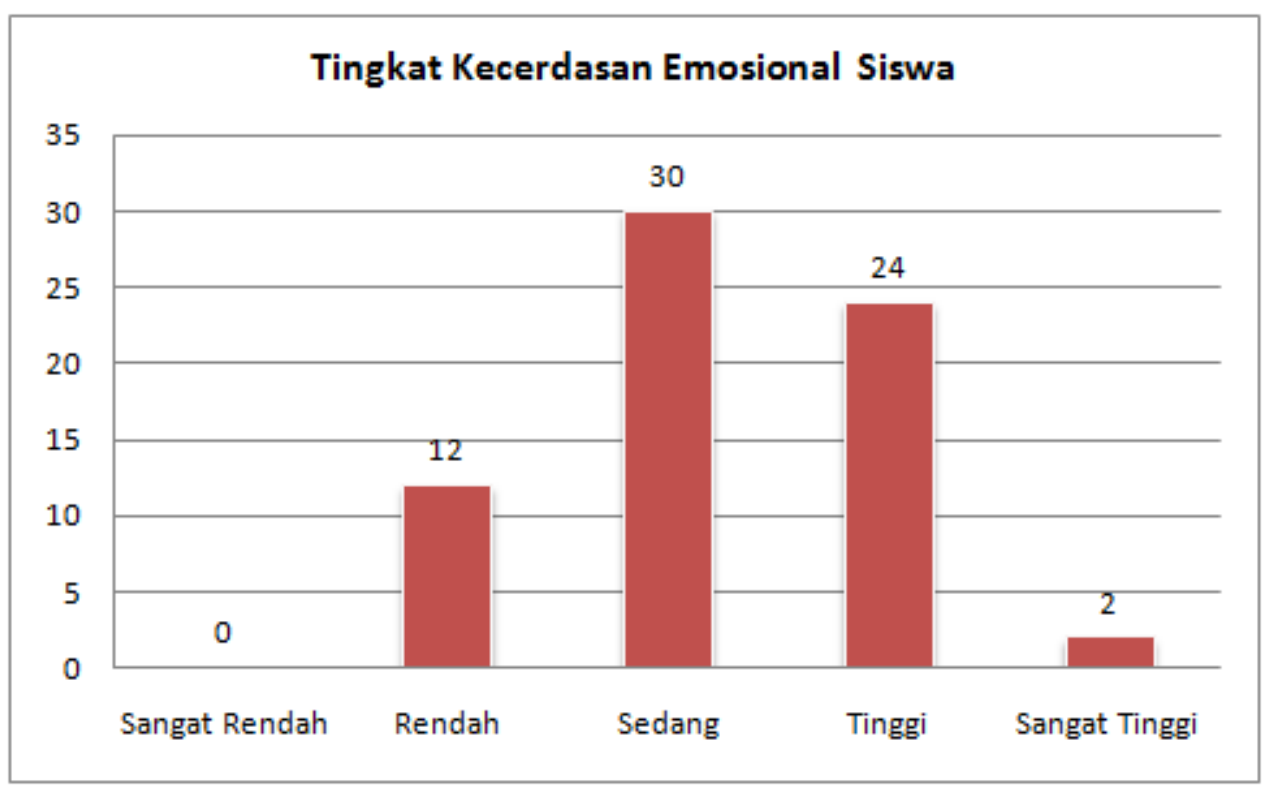

Gambar 1 Distribusi Tingkat Kecerdasan Emosional

Berdasarkan Gambar 1 dari jumlah 68 siswa dapat diketahui bahwa tidak ada siswa yang memiliki kecerdasan emosioal sangat rendah. Sebanyak 12 siswa atau 17,65\% memiliki tingkat kecerdaan emosional rendah, sebanyak 30 siswa atau 44,12\% memiliki tingkat kecerdasan emosional sedang, sebanyak 24 siswa atau 35,29\% memiliki tignkat kecerdasan emosional tinggi dan sebanyak 2 siswa atau 2,94\% memiliki tingkat kecerdasan emosional sangat tinggi. Banyaknya siswa yang memiliki tingkat kecerdasan emosional yang masih berada pada tingkat sedang adalah kenyataan bahwa pengetahuan kecerdasan emosional masih jarang diberikan oleh pendidikan formal dalam meningkatkan kemampuan kecerdasan emosional siswa.

\section{SIMPULAN}

Berdasarkan temuan penelitian ini disimpulkan bahwa partisipan dalam penelitian ini yaitu siswa di SMPN 1 Dukuhseti Kabupaten Pati. Penelitian ini secara umum masih memiliki tingkah kecerdasan emosional yang berada pada kategori sedang atau Cukup. Berdasarkan dari 68 siswa yang menjadi sampel 17,65\% memiliki tingkat kecerdaan emosional rendah, 44,12\% memiliki tingkat kecerdasan emosional sedang, 35,29\% memiliki tignkat kecerdasan emosional tinggi dan 2,94\% memiliki tinkat kecerdasan emosional sangat tinggi. Dari uraian tersebut dapat disimpulkan, bahwa mayoritas siswa SMP N1 Dukuhseti yang memiliki tingkat kecerdasan emosional yang masih berada pada tingkat 
sedang. Meski demikian ada sebagian siswa memiliki kecerdasan emosi tinggi dan masih ada yang memiliki kecerdasan renda, hal itu dapat dipengaruhu faktor internal mauoun ekternal yang dialami tiap-tiap individu. Kenyataan bahwa pngetahuan kecerdasan emosional masih jarang diberikan oleh pendidikan formal dalam meningkatkan kemampuan kecerdasan emosional siswa.

\section{DAFTAR PUSTAKA}

Antiniene, D., \& Lekavičienè, R. (2019). Some Psychologucal Factors That Affect EMotional Intelligent of Lithuanian High School Students. SOCIAL WELFARE INTERDISCIPLINARY APPROACH, 9 (1).

Arikunto, suharsini. 2010. Prosedur Penelitihan : Suatu Pendekatan Praktik. Jakarta: Reka cipta

Bar-On, R. (2006). The Bar-On Model of Emotional-Social Intelligence. Consortium for Research on Emotional Intelligence, 1-28.

Beckford, A. (2018, Agustus 6). the-skills-you-need-to-succeed-in-2020. Dipetik Juli 3, 2020, dari https://www.forbes.com.

Boyatzis, R. E., Goleman, D., \& Rhee, K. (2000). lustering competence in emotional intelligence: Insights from the Emotional Competence Inventory (ECI)s. Consortium for Research on Emotional Intelligence in Organizations .

Carmelia, T., Tiatri, S., \& Wijaya, E. (2017). Hubungan Antara Kecerdasan Emosional Dan Prestasi Akademik Dengan Job Performance Pada Mahasiswa Aktif Organisasi Kemahasiswaan. Jurnal Muara Ilmu Sosial, Humaniora, dan Seni, 184-197 .

Cotrus,, A., Stanciu, C., \& Bulborea, 1. A. (2013). EQ vs. IQ which is most important in the success or failure of a student? Procedia - Social and Behavioral Sciences, 46, 5211 - 5213.

Dhani, P., \& Sharma, T. (2016). Emotional Intelligence; History, Models And Measures. International Journal of Science Technology and Management , 188-201.

Douglas, S. (2015). Incorporating Emotional Intelligence in Legal Education: A Theoretical Perspective. E-Journal of Business Education \& Scholarship of Teaching, 9 (2), 56-71.

Drigas, A. S., \& Papoutsi, C. (2018). A New Layered Model on Emotional Intelligence. Behavioral Science, 8 (45).

Goleman, D. (2015). Emotional Intelligence : Kecerdasan emosional mengapa EI lebih penting daripada IQ. Jakarta: PT. Gramedia Pustaka. Utama.

Hidayati, K. B., \& Farid, M. (2016). Konsep Diri, Adversity Quotient dan Penyesuaian Diri pada Remaja. Persona, Jurnal Psikologi Indonesia, 5 (02), 137 - 144.

http://simkeu.kemdikbud.go.id/index.php/peraturan1/8-uu-undang-undang/12-uu-no-20tahun-2003-tentang-sistem-pendidikan-nasional

Jati, G. W., \& Yoenanto, N. H. (2013). KECERDASAN EMOSIONAL SISWA SEKOLAH MENENGAH PERTAMA DITINJAU DARI FAKTOR DEMOGRAFI. Jurnal Psikologi Pendidikan dan Perkembangan, 2 (2).

Masruroh, A. (2014). Konsep Kecerdasan Emosional dalam Perspektif endidikan Islam. Mudarrisa: Jurnal Kajian Pendidikan Islam, 6 (1), 61-87.

Ross, M. R., \& Powell, S. R. (2002). ew Roles for School Psychologists: Addressing the Social. School Psychology Review , 43-52.

Rupande, G. (2015). The Impact of Emotional Intelligence on Student Learning. International Journal of Managerial Studies and Research (IJMSR), 3 (9), 133-136. 
Schutte, N. S., Malouff, J. M., \& Thorsteinsson, E. B. (2013). Increasing Emotional Intelligence through Training: Current Status and Future Directions. The International Journal of Emotional Education, 5 (1), 56=72.

Subramanian, K. R. (2016). Key to Organisational Effectiveness: Social and Emotional Intelligence. International Research Journal of Advanced Engineering and Science, 1 (4), 127-131.

Sugiyono. (2017). Metode Penelitian Kuantitatif Kualitatif dan R\&D. Bandung: Alfabeta.

Wolff, S. (2005). Book Reviews. Journal of Child Psychology and Psychiatry, 46 (9). 